\title{
IMPACTO DA SUSTENTABILIDADE NA ANÁLISE DO CICLO DE VIDA DO ETANOL BRASILEIRO FRENTE MECANISMOS REGULATÓRIOS INTERNACIONAIS
}

\section{IMPACT OF SUSTAINABILITY IN THE ANALYSIS OF THE LIFE CYCLE OF BRAZILIAN ETHANOL AGAINST INTERNATIONAL REGULATORY MECHANISMS}

\author{
Isabela Ferreira Rosa *Email: isa.ferreira.rosa@gmail.com \\ leda Kanashiro Makiya *Email: iedakm@gmail.com \\ Francisco Ignacio Giocondo Cesar**Email: giocondo.cesar@gmail.com \\ Leonardo Bergamin ${ }^{* *}$ Email: leonardoph2@gmail.com \\ ${ }^{*}$ Faculdade de Ciências Aplicadas (UNICAMP), Limeira, SP, Brasil \\ ${ }^{* *}$ Instituto Federal de São Paulo (IFSP), Piracicaba, SP, Brasil \\ ${ }^{* * *}$ Faculdades Metropolitanas Unidas (FMU), São Paulo, SP, Brasil
}

Resumo: Os biocombustíveis vêm ganhando mercado frente aos combustíveis fósseis devido à necessidade em minimizar a dependência destes últimos. A produção desses biocombustíveis concentra-se em três grandes polos mundiais: EUA, Brasil e União Europeia, que juntos representam aproximadamente $85 \%$ da produção mundial. Ações internacionais foram e estão sendo promovidas ao longo dos anos para aumentar a sustentabilidade dos biocombustíveis em várias etapas de sua cadeia produtiva. Por meio da Análise do Ciclo de Vida, o presente artigo avaliou as metodologias de cálculo das emissões de gases do efeito estufa das regulamentações internacionais e importantes players em termos de biocombustíveis, EUA e UE, RFS2 e EU-RED, respectivamente. A Diretiva Europeia apresenta uma metodologia própria de cálculo, enquanto que a Norte Americana conta majoritariamente com a metodologia GREET para cálculo. Assim, pôde-se observar que a Diretiva Europeia acaba excluindo algumas externalidades de sua análise, como as mudanças indiretas no uso da terra, e a utilização ou queima do biocombustível, acabando por não realizar a análise completa do ciclo de vida desses. Enfatizou-se como as duas metodologias analisam de maneiras tão distintas o etanol de cana-de-açúcar brasileiro. Assim, a importância dessa pesquisa vem ao encontro da necessidade de regulamentação de padrões internacionais de mesma referência na certificação do etanol como uma commodity global.

Palavras-chave: Gases de Efeito Estufa. Etanol. Regulamentações Internacionais. Cana-de-açúcar. Análise do Ciclo de Vida.

Abstract: Biofuels have been gaining market against the fossil fuels because of the need to minimize their dependence on fossil fuels. The production of these biofuels is concentrated in three major world poles: the USA, Brazil and the European Union, which together represents approximately $85 \%$ of world production. International actions have been promoted over the years to increase the sustainability of biofuels in various stages of its production chain. Through the Life Cycle Analysis, the present article evaluated the methodologies for calculation of greenhouse gases emissions from international regulations, and important players in terms of biofuels, USA and EU, RFS2 and EU-RED, respectively. The European Directive has its own calculation methodology, while the North American has a majority of the GREET calculation methodology. Thus, it could be observed that the European Directive ends up excluding some externalities from its analysis, such as indirect land use changes, and the use or burning of biofuels, and therefore do not carry out the full analysis of the life cycle of

Revista Produção Online. Florianópolis, SC, v.17, n. 2, p. 711-732, 2017. 
biofuels. It was emphasized how two methodologies analyze in such different ways the Brazilian sugar cane ethanol. Thus, the importance of this research meets the need to regulate international standards of the same reference in the certification of ethanol as a global commodity.

Keywords: Greenhouse gases. Ethanol. International Regulations. Sugar cane. Life Cycle Analysis.

\section{INTRODUÇÃO}

De acordo com o Instituto de Economia Agrícola (2014), os biocombustíveis vêm ganhando mercado frente aos combustíveis fósseis devido à necessidade em minimizar a dependência destes últimos. No Brasil, o biocombustível mais utilizado e produzido é o etanol proveniente da cana-de-açúcar, cuja fabricação no ano de 2014 foi de $27.543 \mathrm{mil} \mathrm{m}^{3}, 19 \%$ a mais do que na safra do ano anterior (UNICADATA, 2014). Estudos indicam que o aumento mundial no consumo da energia renovável deve-se a adoção de adições de biocombustíveis a gasolina e diesel feita por cerca de 60 países, até 2013 (UNICA, 2014).

Os biocombustíveis comercialmente disponíveis, como etanol, biodiesel e biogás apresentam reduções de emissão de $\mathrm{CO}_{2}$ em relação aos combustíveis convencionais e até o momento são as únicas opções disponíveis no mercado em quantidade suficiente para substituir parte dos combustíveis provenientes de fontes fósseis (WBA, 2013).

A produção desses biocombustíveis concentra-se em três grandes polos mundiais: EUA, Brasil e União Europeia, que juntos representam aproximadamente $85 \%$ da produção mundial (UNICA, 2014). De acordo com projeções, a União Europeia, os Estados Unidos e o Brasil são os três maiores consumidores de biocombustíveis e deverão representar $78 \%$ de bioetanol total e $65 \%$ de biodiesel total consumido em 2024 (OECD/FAO, 2015). Portanto, os condutores de política nesses países são particularmente importantes em se tratando de biocombustíveis. O setor sucroenergético no Brasil é uma importante divisão na pauta das exportações brasileiras, sendo que no ano de 2013 representou $5,7 \%$ desta (DEPEC, 2015).

Ações internacionais foram e estão sendo promovidas ao longo dos anos para aumentar a sustentabilidade dos biocombustíveis em várias etapas de sua cadeia produtiva (ROLLANO et al., 2015). Assim, essas iniciativas procuram promover, durante o ciclo de vida do biocombustível, uma produção e distribuição que busque mitigar os efeitos negativos sobre as três dimensões da sustentabilidade 
(COMISSÃO MUNDIAL SOBRE MEIO AMBIENTE E DESENVOLVIMENTO, 1987): econômica, social e ambiental.

Diante disso, o presente estudo buscou analisar o impacto da sustentabilidade na Análise do Ciclo de Vida do etanol, frente os Mecanismos Regulatórios Internacionais, mais especificamente uma iniciativa que ocorre nos EUA, importante produtor de biocombustíveis e importador do etanol brasileiro (DEPEC, 2015), Renewable Fuel Standard 2 (RFS2), ligada a Environmental Protection Agency (EPA), que estabelece que no prazo de até 2022 haja um volume mandatório de mistura de combustíveis renováveis a gasolina (UNICA, 2010); e as Diretivas Europeias de Energia Renovável - EU-RED (Directiva 2009/28/CE), que, dentre as suas medidas, estabelece reduções na intensidade de gases de efeito estufa (GEE) emitidos no setor de transporte rodoviário e não-rodoviário, porém com regulações no processo produtivo, aumentando assim a participação de combustíveis renováveis na União Europeia.

\section{DESENVOLVIMENTO}

\subsection{Metodologia}

O foco da pesquisa é analisar a aderência entre as duas políticas internacionais para combustíveis renováveis, do ponto de vista da utilização da metodologia das emissões de Gases do Efeito Estufa durante o ciclo de vida dos biocombustíveis. Para atingir esse objetivo, o estudo apresenta uma abordagem qualitativa e quantitativa, cujos objetivos têm caráter exploratório, buscando traçar um paralelo entre ambas metodologias utilizadas.

De acordo com Marconi e Lakatos (2010), o método comparativo constitui uma "experimentação direta", a qual se pode fazer por meio de dados qualitativos. Além disso, esse método pode ser atrelado a outros e, no presente trabalho, foi usado também o método descritivo, a fim de analisar os "elementos de estrutura" das ações governamentais internacionais abordadas. Esses elementos de estrutura são os critérios de sustentabilidade presentes em cada uma das ações governamentais analisadas. 
A coleta de informações embasou-se na pesquisa bibliográfica e documental relacionada aos critérios de sustentabilidade presentes nas ações regulatórias governamentais em análise: o RFS-2 e o EU-RED, além da leitura de trabalhos que dissertaram a respeito do tema, com intuito de se obter o estado da arte em se tratando dessa discussão.

Assim, aplicou-se também a metodologia de Análise do Ciclo de Vida (ACV) do biocombustível etanol de cana-de-açúcar, presentes em ambas metodologias de cálculo das emissões de GEE, sendo que, com base nessa metodologia, a Agência de Proteção Ambiental Norte Americana (Environmental Protection Agency - EPA, 2015) divide o Ciclo de Vida para os biocombustíveis da seguinte maneira:

Figura 1 - Ciclo de vida de biocombustíveis renováveis

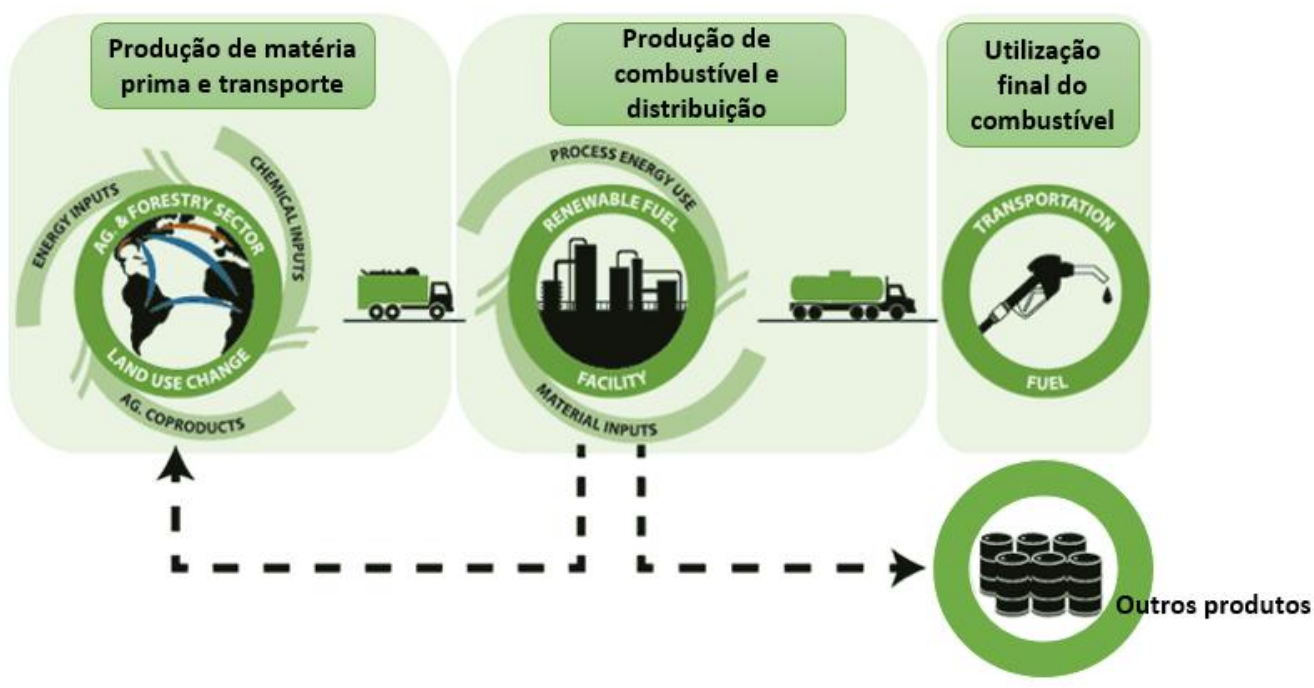

Fonte: EPA (2015).

Baseando-se na figura 1, a primeira etapa consiste na produção e transporte da matéria-prima, seguida pela produção e distribuição, e por fim, o uso final do biocombustível. Com base nessa divisão do ciclo de vida, utilizaram-se essas fases para comparar uma tabela de valores padrões da metodologia GREET, adotada pelo RFS2 e a metodologia própria, adotada pela EU-RED, mas que por sua vez adota como modelo de cálculo a ferramenta BioGrace.

\subsection{Revisão da Literatura}


A Análise do Ciclo de Vida é uma técnica de avaliação do desempenho ambiental de um determinado produto (QUEIROZ; GARCIA, 2010), que fornece uma análise holística sobre o produto, levando em conta potenciais impactos de todas as fases de vida deste; desde a produção até a gestão do final de vida do mesmo. Assim, essa ferramenta serve de análise para tomadas de decisões, e deve oferecer dados concisos de modo a alcançar os objetivos desejados. Visando tornar essa análise cada vez mais padronizada, a International Organization for Standardization (ISO) criou a série de normas da ISO 14040, cujos elementos podem ser divididos basicamente em quatro: (1) definição do objetivo e escopo do estudo; (2) identificação e quantificação do meio ambiente envolvido; (3) avaliação do potencial de impactos nesse meio; (4) análise das opções disponíveis para reduzir os impactos ambientas (VON BLOTTNITZ; CURRAN, 2007). Entre as abordagens e ferramentas que mais comumente fazem a avaliação os impactos ambientais dos biocombustíveis com base no ciclo de vida são (CURRAN, 2013):

- Gestão de Carbono / Carbon Footprint;

- Pegada ecológica;

- Análise energética;

- Análise do Ciclo de Combustível;

- Análise de Gases de Efeito Estufa do Ciclo de Vida;

- Avaliação do Ciclo de Vida;

- Avaliação de Riscos do Ciclo de Vida;

- Análise de Fluxo de Materiais;

- Saldo Líquido Energia;

- Indicadores de Sustentabilidade.

De acordo com a ABNT a Análise do Ciclo de Vida é dividida em quatro fases: a definição do objetivo e escopo do estudo, análise do Inventário do Ciclo de Vida, Avaliação dos Impactos Ambientais associados ao sistema e Interpretação dos resultados, com base na primeira etapa de definição dos objetivos (MARCAL et al., 2013).

Assim, visando uma redução das emissões de GEE durante o ciclo de vida dos combustíveis, países tem adotado a prática de substituir os combustíveis fósseis por biocombustíveis ou mesmo inseri-lo do combustível convencional, por meio das chamadas adições. Essas adições de biocombustíveis a combustíveis fósseis variam Revista Produção Online. Florianópolis, SC, v.17, n. 2, p. 711-732, 2017. 
de país para país, de acordo com o mandato vigente imposto pelo governo local. A tabela 1 demonstra as relações de misturas em determinados países.

Tabela 1 - Mistura de biocombustíveis ao combustível fóssil por país

\begin{tabular}{ll}
\hline País & Porcentagem de mistura \\
\hline Brasil & $27 \%$ de etanol e $5 \%$ de biodiesel \\
Argentina & $5 \%$ de etanol e $10 \%$ de biodiesel \\
Canadá & $5 \%$ de etanol e $2 \%$ de biodiesel \\
China & $10 \%$ de biocombustíveis em nove províncias \\
Estados Unidos & $10 \%$ de etanol e $10 \%$ de biodiesel \\
Índia & $5 \%$ de etanol \\
Paraguai & $24 \%$ de etanol e $1 \%$ de biodiesel \\
União Europeia & Em média $5 \%$ de combustíveis renováveis \\
\hline
\end{tabular}

Fonte: Adaptado de UNICA (2014).

O Brasil apresenta maiores porcentagens de mistura de biocombustíveis aos combustíveis fósseis que os EUA e que a China, sendo que esses dois últimos são os maiores emissores de GEE mundiais: o primeiro é o maior em termos per capita e o segundo em termos absolutos. Um dos fatos que justificam a liderança da China em emissões é o grande tamanho da população (concentra de $20 \%$ a $25 \%$ da população mundial) (EMBRAPA, 2015). Os Estados Unidos apresentam políticas voltadas ao incremento no consumo de combustíveis renováveis com sua Agência de Proteção Ambiental (EPA).

\subsection{Desenvolvimento e Discussão}

Conforme visto anteriormente, os três maiores atores em termos de biocombustíveis são EUA, Brasil e União Europeia. E, por se tratarem de países que, além da produção interna, comercializam biocombustíveis entre si, as políticas públicas praticadas por tais agentes é de suma importância para as tomadas de decisões dos demais governos. Dessa forma, nessa seção serão analisadas as ações governamentais ligadas aos biocombustíveis nas esferas nacional e internacional.

\subsubsection{Regulamentação norte americana}

Os Estados Unidos da América apresentam uma regulamentação promovida e implementada por sua Agência de Proteção Ambiental (EPA) que é a RFS2 (Renewable Fuel Standard); trata-se de uma expansão do RFS1, que busca Revista Produção Online. Florianópolis, SC, v.17, n. 2, p. 711-732, 2017. 
aumentar a quantidade mandatória de volume de biocombustíveis presentes no combustível até o prazo de 2022. Dessa forma, é de responsabilidade da EPA garantir que haja um volume mínimo de biocombustível presente em energias utilizadas para o transporte (EPA, 2014).

Essa regulamentação influencia o aumento no consumo dos biocombustíveis, porém apresenta alguns critérios de sustentabilidade para o consumo destes chamados de restrições, que estabelecem práticas sustentáveis no processo produtivo do biocombustível para sua comercialização dentro do país. Esses critérios são relacionados (NL AGENCY, 2011):

- Às emissões de gases de efeito estufa (GEE) de combustíveis renováveis;

- Aos tipos de matéria-prima utilizadas;

- Aos tipos de terra que podem ser utilizados para o plantio e colheita das matérias-primas (mudança e uso da terra direto e indireto).

Cumpre salientar que estes dois últimos critérios se combinam em um, formando a biomassa renovável, que é a matéria-prima dos biocombustíveis. E, quanto a matéria prima utilizada, se ela for de origem agrícola, as terras onde elas serão plantadas são monitoradas pela EPA; se forem de origem não agrícola (florestas), elas devem estar de acordo com as normas especificadas para esse tipo de extração (NL AGENCY, 2011).

Neste sentido, o RFS1, criado em 2005, se difere do RFS2, de 2010, primeiramente no que tange a quantidade de mistura de biocombustíveis presentes no combustível comercializado nacionalmente, pois houve um aumento desta; a classificação dos biocombustíveis, que passaram a estar em quatro diferentes ramos, de acordo com a porcentagem de redução das emissões de GEE em relação a gasolina, sendo o primeiro deles relacionado aos combustíveis renováveis tradicionais, que representam uma redução de até $20 \%$ (etanol de milho, sorgo), o segundo abrange os biocombustíveis avançados, redução de até $50 \%$ (etanol de cana-de-açúcar, gás liquefeito), o terceiro são os combustíveis diesel de biomassa, redução de até $50 \%$ (proveniente de óleo de soja, canola, alga) e por último os biocombustíveis celulósicos, redução de até 60\% (proveniente de materiais celulósicos, como gramíneas) (SCHNEPF; YACOBUCCI, 2013). 
Os componentes presentes no cálculo de emissões de GEE no ciclo de vida dos biocombustíveis são (FEDERAL REGISTER, 2009):

a) Produção da matéria prima: são considerados os impactos diretos e indiretos do crescimento das matérias-primas, tanto para as produções nacionais, quanto importadas. Entres os pontos analisados estão o uso de fertilizantes e energia;

b) Mudanças no uso da terra: esse componente está relacionado a mudanças no uso da terra devido ao incremento da demanda de biocombustíveis por parte dos EUA, para iniciar um cultivo de produto agrícola, que pode acabar por aumentar as emissões de GEE;

c) Transporte de matéria prima: é o transporte da matéria prima do campo para o ponto de beneficiamento e do ponto de beneficiamento para o ponto de uso desta;

d) Processamento: esse componente varia de acordo com o número de suposições e no número de variáveis associadas nas produções domésticas e internacionais;

e) Transporte do combustível: neste ponto são consideradas as emissões de transporte e distribuição;

f) Tubo de escape de combustão: emissão da combustão dos biocombustíveis é baseado no teor de carbono presente em cada um dos combustíveis.

De acordo com GRISOLI e COELHO (2011) essa normativa apresenta um caráter voltado para a segurança energética do país, uma vez que seus objetivos estão ligados a uma maior independência e segurança energética para os EUA.

A figura 2, abaixo, mostra os limites de cálculo das emissões de GEE, além disso aponta as diversas metodologias utilizadas pelo mesmo.

Figura 2 - As fronteiras do sistema e os modelos utilizados 


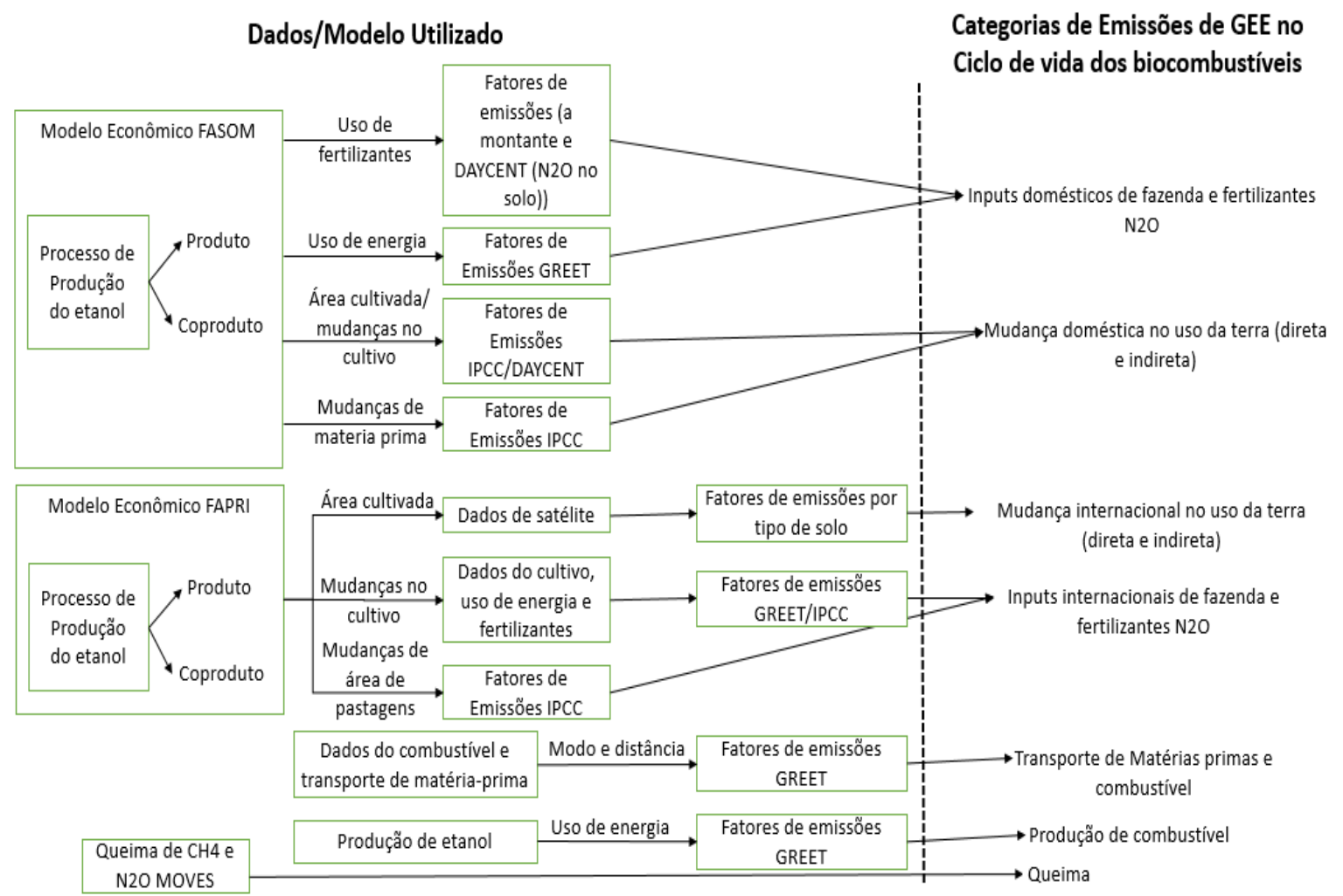

Fonte: Adaptado de EPA (2010)

Conforme observado acima, a metodologia Gases de Efeito Estufa, Emissões Regulamentadas, e Uso de Energia em Transporte (The Greenhouse gases, Regulated Emissions, and Energy use in Transportation Model GREET) - é a mais utilizada; neste sentido, tomou-se um exemplo para análise comparativa entre as metodologias de emissões de GEE Europeia e Norte Americana.

A metodologia GREET inclui as emissões de GEE associadas desde a produção até combustão dos combustíveis fósseis (diesel, gasolina, gás natural, carvão, etc.) e biocombustíveis. Esta também estima as emissões de GEE associadas à produção de eletricidade necessária para a agricultura e a produção de biocombustíveis. No que tange ao setor agrícola, fornece dados das emissões associadas a produção e transporte de insumos agrícolas, tais como fertilizantes, herbicidas, pesticidas. Além disso, ela tem estado em desenvolvimento há vários anos e passou por uma extensa avaliação através de múltiplas atualizações, o que a tornou mais refinada (EPA, 2010).

\subsubsection{Regulamentação europeia}

Revista Produção Online. Florianópolis, SC, v.17, n. 2, p. 711-732, 2017. 
Em 2009 foi implementada uma regulação na União Europeia ligada aos biocombustíveis e ao avanço no consumo deles; esta é a Diretiva 2009/28/CE ou Renewable Energy Directive (EU-RED). Essa Diretiva provém de um programa da União Europeia, que estabelece como um dos objetivos que $10 \%$ da energia consumida no transporte nos 28 Estados-membros que formam a União tenha origem em fontes limpas até o ano de 2020. A energia renovável pode prover de diversas fontes, porém, em setores específicos, como o de transporte, o recurso chave é o biocombustível. Assim, os Estados-membros são incentivados a implantarem esquemas de suporte internos que promovam o uso de energias renováveis (ICTSD, 2010).

Neste sentido, a Diretiva trabalha em duas ramificações diferentes, sendo a primeira delas a crescente preocupação com o fornecimento de energia e a segunda a necessidade de redução de emissões dos GEE. Porém, para que esse fornecimento de energias renováveis ocorra de forma livre, o Artigo 17 da diretiva traz dois conjuntos de critérios de sustentabilidade para os biocombustíveis: mitigar a emissão de gases do efeito estufa e atender aos requisitos de uso da terra (ICTSD, 2010).

Destarte, a Diretiva estabeleceu a meta de reduzir em 6\% a emissão de GEE nos combustíveis utilizados no transporte rodoviário e não rodoviário. No que tange ao uso da terra, estabeleceu-se a restrição ao limite de $5 \%$ do uso de biocombustíveis provenientes de terras com culturas de alimentos (ICTSD, 2010).

A Diretiva especifica o método de cálculo dos GEE como sendo a soma entre: extração do cultivo de matérias primas, mudanças no uso do solo, processamento, transporte e distribuição. Neste índice não são consideradas as emissões líquidas de gases no uso final do biocombustível, uma vez que, segundo o relatório do International Centre for Trade and Sustainable Development de 2010, são consideradas nulas, pois equivalem ao carbono consumido pelas plantas enquanto matérias primas.

De acordo com Denvir (2014), os critérios de sustentabilidade obrigatórios da Diretiva objetivam mitigar as emissões de GEE, proteger a biodiversidade e proibir o cultivo de matérias primas em locais com alto estoque de carbono, como apresentado na tabela 2. Porém, alguns critérios acabam ficando como secundários, 
e neste interim, o autor classifica-os em grupos de acordo com o nível de importância dentro da regulamentação:

1. Compulsório: critério mínimo de sustentabilidade que os biocombustíveis devem ter;

2. Flexível: questões sobre as quais os países membros possuem flexibilidade para decidir;

3. Incerto: assuntos que não foram decididos ainda.

Tabela 2 - Nível de importância do critério na Diretiva Europeia

\begin{tabular}{lcc}
\hline Critério & Artigo & Grupo \\
\hline Critério de GEE & $17(2), 19$ & 1 \\
Critérios de Terra & $17(3-5)$ & 1 \\
Política Agrícola Comum & $17(6)$ & 1 \\
Desperdícios e Resíduos & $17(1), 19(3), 21(2) 2$ & 2 \\
Relatório de Conformidade Regional & $19(2)$ & 2 \\
Mudança indireta no uso da terra & $19(6)$ & 3 \\
Sustentabilidade mais ampla para parte ambiental e & $17(7)$ & 3 \\
social & & \\
\hline
\end{tabular}

Fonte: DENVIR (2014)

Assim, dentro do processo de cálculo das emissões de GEE são levados em conta durante o ciclo de vida do produto, as mudanças de uso da terra, cultivo e colheita, restos de material, transporte e estoque, produção do biocombustível, transporte até o cliente. Neste contexto, percebe-se que a Diretiva tem como incerto o critério de mudanças indiretas no uso da terra (substituição de culturas alimentares por de bioenergia) (DENVIR, 2014).

A Diretiva 2009/28/CE aponta que as metas de aumento na utilização de energias renováveis devem ser compartilhadas entre os Estados-Membros de modo a tornar a quota ponderada em função do Produto Interno Bruto (PIB), além de levar em consideração o consumo bruto final de energia de cada país. A meta de consumo de $10 \%$ de energia proveniente de fontes renováveis para o setor de transporte é aplicável a todos os Estados-membros, por meio da alegação de que se o Estado não prover dessas fontes renováveis, existe uma facilidade em adquirir de outros Estados-Membros que a tenham em excesso (EUROPEAN COMMISSION, 2009).

Outra Diretiva que abrange os biocombustíveis é a Diretiva sobre a qualidade dos combustíveis (Diretiva 2009/30/CE) que, por sua vez, também fixa os critérios Revista Produção Online. Florianópolis, SC, v.17, n. 2, p. 711-732, 2017. 
correspondentes no que diz respeito aos biocombustíveis, tendo por exigência a redução de 6\% das emissões de GEE até 2020, comparado a 2010 (metas indicativas de $2 \%$ para 2014 e $4 \%$ para 2017); e redução $2 \%$ em emissões de GEE para novas tecnologias em desenvolvimento, como captura e armazenagem de $\mathrm{CO}_{2}$, também comparado ao ano de 2010 (EUROPEAN COMMISSION, 2009).

Assim, os critérios de sustentabilidade de ambas as Diretivas Europeias tangem três principais assuntos que são: redução das emissões de GEE, Biodiversidade e Uso do solo, conforme tabela 3, abaixo.

Tabela 3 - Critérios de Sustentabilidade das Diretivas Europeias

\begin{tabular}{ll}
\hline \multicolumn{2}{c}{ Critérios de sustentabilidade para as Diretivas Europeias } \\
\hline & Mínimo de 35\% de redução de GEE; redução de \\
Redução de emissões de GEE & $50 \%$ em 2017; redução de 60\% a partir de 2018, \\
& para novas instalações, comparados com os \\
& combustíveis fósseis que vão substituir. \\
Biodiversidade & Não serem produzidos a partir de matérias primas \\
& obtidas em área de elevada biodiversidade, \\
& incluindo floresta primária. \\
Uso do Solo & Não serem produzidas a partir de matérias primas \\
& obtidas em solos com elevado teor de carbono; por \\
& exemplo, áreas pantanosas, turfeiras e áreas \\
& florestais. \\
\hline
\end{tabular}

Fonte: Adaptado de ENMC (2016)

De acordo com o anexo IV da Diretiva Europeia 2009/30/CE, as emissões de gases de efeito estufa provenientes da produção e utilização de combustíveis para transportes, biocombustíveis e biolíquidos são calculadas pela seguinte fórmula (EUROPEAN COMMISSION, 2009):

$E=e e c+e l+e p+e t d+e u-e s c a-e c c s-e c c r-e e e$,

Onde:

$E$ = emissões totais da utilização do combustível;

eec = emissões provenientes da extração ou cultivo de matérias-primas;

el = contabilização anual das emissões provenientes de alterações do carbono armazenado devidas a alterações do uso do solo;

ep = emissões do processamento;

etd = emissões do transporte e distribuição;

eu = emissões do combustível na utilização; 
esca $=$ redução de emissões resultante da acumulação de carbono no solo através de uma gestão agrícola melhorada;

eccs = redução de emissões resultante da captura e fixação de carbono e armazenamento geológico de carbono;

eccr = redução de emissões resultante da captura e substituição de carbono; e

eee $=$ redução de emissões resultante da produção excedentária de eletricidade na cogeração.

Não são levadas em conta as emissões da fabricação de máquinas e equipamento, apenas as emissões decorrentes da utilização destes. As emissões de gases com efeito de estufa dos combustíveis, E, são expressas em gramas de CO2 equivalente por MJ de combustível, gCO2eq/MJ.

A redução de emissões de gases com efeito de estufa dos biocombustíveis e biolíquidos é calculada pela seguinte fórmula:

REDUÇÃO = $(E F-E B) / E F$

Onde:

EB = emissões totais do biocombustível ou biolíquido; e

$E F=$ emissões totais do combustível fóssil de referência.

No ciclo de vida da cana-de-açúcar em sua transformação em etanol existe a liberação de uma série de gases provenientes da plantação, como o caso de agrotóxicos, que acabam por liberar $\mathrm{N}_{2}$ na atmosfera. Nesse sentido, a UE estabeleceu que os GEE considerados são o $\mathrm{CO}_{2}, \mathrm{~N}_{2} \mathrm{O}$ e $\mathrm{CH}_{4}$. Para efeitos do cálculo da equivalência de $\mathrm{CO}_{2}$, estes gases têm os seguintes valores: $\mathrm{CO}_{2}: 1 ; \mathrm{N}_{2} \mathrm{O}$ : 296; $\mathrm{CH}_{4}$ : 23 (EUROPEAN COMMISSION, 2009). Esses fatores de conversão são conhecidos por "Global Warming Potencial" (GWP), ou Fator de Aquecimento Global, e foram criados com a finalidade de permitir a comparação entre diferentes gases na influência sobre o aquecimento global. Assim, essa métrica traz informações sobre a quantidade de energia que será absorvida, em um período (no caso 100 anos), com a emissão de 1 tonelada de um determinado gás, em relação à emissão de 1 tonelada de dióxido de carbono $\left(\mathrm{CO}_{2}\right)$, ou seja, quanto maior o GWP, maior será o aquecimento do planeta em relação ao $\mathrm{CO}_{2}$ (EPA, 2016).

\section{ANÁLISE COMPARATIVA DOS MODELOS REGULATÓRIOS}


De acordo com a NL Agency (2011), as legislações estudadas da UE e dos EUA de biocombustíveis são incomparáveis tanto em sua estrutura, como nas definições utilizadas, os requisitos de sustentabilidade, relatórios e metodologias de cálculo. As diferenças mais importantes (para os produtores de biocombustíveis) podem ser encontradas nos requisitos de redução das emissões de GEE, a metodologia de cálculo de redução de emissões de GEE e da maneira que a mudança no uso da terra é incorporada.

Atualmente, não existem requisitos ligados a Diretiva Europeia relacionados a mudanças indiretas no uso da terra, ou seja, quando as terras antes eram utilizadas para culturas alimentícias e são convertidas para culturas de bioenergia. Porém, a Diretiva faz um monitoramento interno no bloco europeu no que tange a esse requisito. Já no que tange a RFS2 existe esse requisito mais explícito e que inclusive é um dos componentes da metodologia de cálculo das emissões de GEE.

De acordo com Rein (2012), entre os maiores assuntos e preocupações relacionados a aferição das emissões de GEE são:

- Fronteiras do Sistema: estas procuram indicar o que está incluso no cálculo das emissões;

- Efeitos Diretos e Indiretos, sendo que os efeitos diretos são basicamente os combustíveis e energia para a transformação de algo; já os indiretos são a energia requerida para a produção de fertilizantes e produtos químicos;

- Mudança no uso da terra: mudanças no estoque de carbono da terra. $\mathrm{Na}$ maioria das vezes consideram-se apenas mudanças diretas;

- Lidar com coprodutos: o método de alocação das emissões em produtos diferentes pode gerar cálculos diferentes;

- Padrões e dados secundários: sempre é necessário assumir alguns valores padrão, devido à falta de dados; e

- Energia embutida em bens de capital: emissões associadas com bens de capital são normalmente inclusas em cálculos na América e excluídas na Europa.

Assim, no âmbito dessa metodologia, a figura 3 demonstra a diferença da abrangência considerada na cadeia produtiva entre o RFS2 e a EU-RED 
(2009/30/CE) para cálculo dos impactos da sustentabilidade, principalmente sobre alguns temas, como cálculo das emissões de gases.

Figura 3 - Diferença do escopo das cadeias produtivas entre RFS2 e EU-RED2009/30/CE

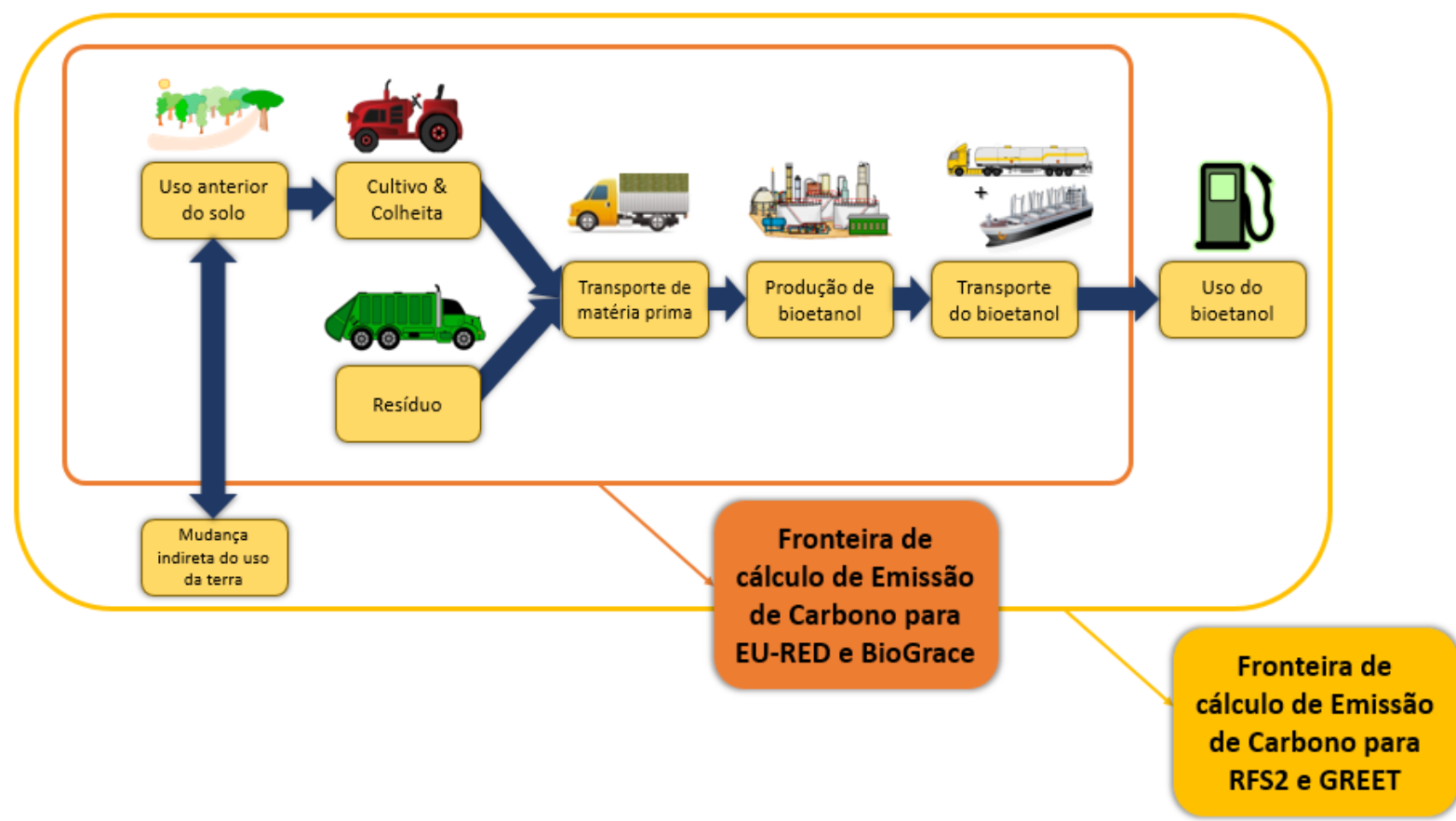

Fonte: Adaptado de DENVIR (2014)

A partir da figura 3 pode-se confirmar que o processo de cálculo das emissões de GEE na Diretiva Europeia abrange os processos de 2 a 7 da cadeia produtiva dos biocombustíveis, enquanto que na regulamentação Norte Americana, a RFS2, a metodologia de cálculo abrange desde o processo 1 até o 8. A partir desse diagnóstico, pode-se afirmar que a metodologia utilizada pela RFS2 é mais abrangente do que a utilizada pela Diretiva Europeia, uma vez que esta última não considera nos cálculos a Mudança Indireta no Uso da Terra e nem a parte de utilização do biocombustível pelo consumidor final.

Em termos de coproduto, quando se tem a produção do etanol de cana-deaçúcar, tem-se a formação de bagaço após a extração do suco; esse bagaço pode ser queimado, gerando um coproduto da produção de etanol, que é a geração de energia excedente, a qual pode ser utilizada para movimentar a usina, fazendo com que a mesma não necessite de energia externa para funcionar, e muitas vezes esta cogeração excede a necessidade da usina e é revendida para iluminação pública ou privada (NOVACANA, 2016).

Revista Produção Online. Florianópolis, SC, v.17, n. 2, p. 711-732, 2017. 
O processo de geração de energia excedente é contabilizado como um crédito de emissões de Gases de Efeito Estufa para o produto (etanol), e esse processo é chamado de alocação. Porém, de acordo com Cherubini et al. (2011) existe uma série de controvérsias a respeito da definição de alocação de energia em sistemas na literatura. No caso das regulamentações internacionais, ambas consideram a alocação.

No que tange a análise metodológica da Diretiva Europeia e a Regulamentação Norte Americana para combustíveis renováveis, os valores padrão utilizados para o etanol Brasileiro de cana-de-açúcar estão apresentados abaixo na tabela 4.

Tabela 4 - Emissões de GEE por mecanismo: GREET e EU-RED para o etanol de cana de açúcar produzido no Brasil

\begin{tabular}{|c|c|c|c|}
\hline ETAPAS & $\begin{array}{c}\text { GREET (BRAZIL) } \\
\text { gCO2/MJ }\end{array}$ & ETAPAS & $\begin{array}{c}\text { EU-RED (BRAZIL) } \\
\text { gCO2/MJ }\end{array}$ \\
\hline $\begin{array}{l}\text { Produção de } \\
\text { Fertilizantes }\end{array}$ & 5,00 & Cultivo & 14,45 \\
\hline Fertilizante N2O & 4,00 & & \\
\hline Usina & 5,00 & & \\
\hline Produção de Etanol & 3,00 & Processamento industrial & 0,85 \\
\hline $\begin{array}{l}\text { Transporte e } \\
\text { distribuição }\end{array}$ & 11,00 & Transporte Rodoviário & 0,85 \\
\hline Combustão & 1 & Transporte para o porto & 8,14 \\
\hline $\begin{array}{l}\text { Mudança direta no } \\
\text { uso da terra }\end{array}$ & 16,00 & Estação de tratamento & 0,40 \\
\hline TOTAL & 45,00 & TOTAL & 24,69 \\
\hline
\end{tabular}

Fontes: GRISOLI (2011); WANG et al. (2012)

A figura 4 demonstra as etapas e valores padrões adotados por ambas regulamentações em uma comparação de valores e demonstrando em qual etapa encontra-se a maior quantidade de emissões de GEE. Na abordagem da EU-RED 2009/30/CE foi utilizada a metodologia Well-to-Wheels, ou do poço às rodas, porém na regulamentação é explicitado que as emissões na queima ou utilização dos biocombustíveis tem-se uma emissão que é considerada nula (GRISOLI, 2011).

Assim, para efeito de comparabilidade, os resultados de emissões de cada uma das etapas da análise do ciclo de vida do etanol de cana-de-açúcar foram agrupadas em quatro de grandes grupos, sendo eles: 
- Cultivo: engloba fazes de produção da matéria prima, com emissões de produção e utilização de fertilizantes e fertilizantes, utilização de queimada para a colheita da cana-de-açúcar, decomposição de raízes e palha que fica no solo; queima de combustível para movimentação do maquinário no campo e transporte da matéria prima do campo à usina;

- Processamento: produção do etanol de cana de açúcar, ou seja, emissões decorrentes de utilização de maquinário, e insumos para a produção;

- Transporte e distribuição: envolve a logística nacional e internacional de distribuição do biocombustível;

- Utilização: queima do combustível no veículo para gerar o movimento.

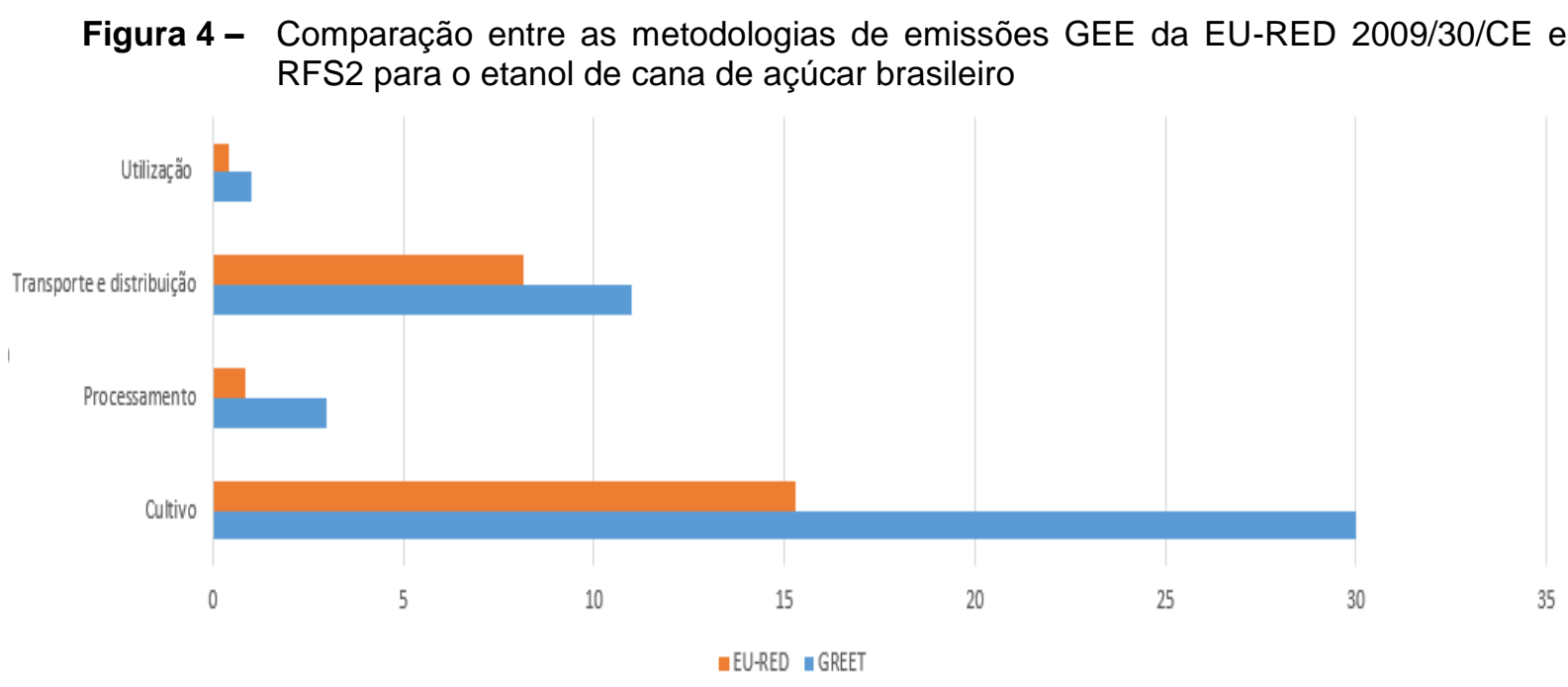

Fonte: elaboração própria.

A metodologia GREET, uma das utilizadas pelos EUA incorpora mudanças indiretas no uso da terra, porém é possível afirmar de antemão que apesar de não estarem explicitados os cálculos desse item na tabela, a metodologia de cálculo das emissões da RFS2 é mais abrangente e criteriosa que a EU-RED. Assim, com base na figura 4, observa-se que o mecanismo regulatório Americano considera mais variáveis no cálculo de emissões de GEE, considerando a análise do ciclo de vida do etanol.

Além disso, vale ressaltar que o setor de cultivo é o que apresenta maiores emissões de Gases de Efeito Estufa, pois incorpora fatores que atualmente são 
inerentes a produção da matéria-prima do estudo, como queimada da cana-deaçúcar para a colheita, emissões devido a utilização de fertilizantes à base de nitrogênio, decomposição de raízes e palha após a queima da cana-de-açúcar, emissões devido a utilização de combustível para gerar o movimento do maquinário no campo e transporte da matéria do campo à usina (ANL 2016) e (BIOGRACE 2015).

Vale ressaltar ainda que o setor de transporte e distribuição envolve 0 transporte da usina até o porto, do porto nacional até o porto internacional, bem como a distribuição do produto em solo estrangeiro; por conta disso, o transporte acaba onerando o produto em termo de emissões de Gases do Efeito Estufa (ANL 2016) e (BIOGRACE 2015).

\section{CONSIDERAÇÕES FINAIS}

Baseando-se na Análise de Ciclo de Vida do etanol, no qual a metodologia engloba do "berço a cova", pode-se observar que a Diretiva Europeia acaba excluindo algumas externalidades de sua análise, como as mudanças indiretas no uso da terra, e a utilização do biocombustível, acabando por não realizar a análise completa do ciclo de vida dos biocombustíveis.

Em uma análise mais detalhada, observa-se que o ciclo produtivo do etanol concentra a maior parte das emissões na etapa de cultivo, que engloba a utilização de fertilizantes e agrotóxicos nas plantações, cujos impactos ambientais são de maior criticidade frente os mecanismos regulatórios americano e europeu.

O mecanismo regulatório americano RFS2 é mais abrangente que a Diretiva Europeia em termos de fronteiras da metodologia e até por esse motivo acaba por possuir um valor padrão de emissões maior que a EU-RED 2009/28/CE. Isso se torna relevante, uma vez que o mesmo etanol brasileiro pode contabilizar emissões de GEE diferentemente para esses dois importantes mercados, em relação ao seu volume de exportação, de acordo com os diferentes padrões de cálculos impostos.

Em termos de redução de emissões de GEE do etanol em relação a gasolina é considerada diferente tanto em termos do ano base tomado para análise da gasolina em relação ao etanol, como do valor que representa essa redução para ambas as regulamentações em estudo. No caso do Diretiva Europeia é considerada uma redução de $71 \%$ nas emissões de GEE, ou seja, o total considerado para a Revista Produção Online. Florianópolis, SC, v.17, n. 2, p. 711-732, 2017. 
gasolina é de 83,8 gCO2eq/MJ, enquanto que o total do etanol foi de aproximadamente $24 \mathrm{gCO} 2 \mathrm{eq} / \mathrm{MJ}$. O ano tomado como base para os cálculos é o de 2008.

Enquanto isso, para o RFS2 coloca o etanol de cana-de-açúcar com uma redução de $50 \%$ das emissões, em relação a gasolina, e o classifica como um biocombustível avançado. Assim, o valor total de emissões para esta regulamentação gira em torno de $45 \mathrm{gCO} 2 \mathrm{eq} / \mathrm{MJ}$, e o valor base considerado é de 90,2 gCO2eq/MJ, sendo que para esse não se encontrou parâmetro de ano para o IPCC (ANL 2016) e (BIOGRACE 2015).

Assim, a importância dessa pesquisa vem ao encontro da necessidade de regulamentação de padrões internacionais de mesma referência na certificação do etanol como uma commodity global. Dessa forma, a discussão de diferentes metodologias de cálculo de emissões de GEE torna-se fundamental para a busca de padrões únicos internacionais para a comercialização do etanol de cana-de-açúcar em nível mundial como um único produto, e consequentemente, um único padrão de referência para diferentes mercados.

\section{REFERÊNCIAS}

ANL. ARGONNE NATIONAL LABORATORY. Greenhouse Gases, Regulated Emissions and Energy Use in Transportation (GREET) Model 2016. Disponível em: <http://greet.es.anl.gov/>. Acesso em: 30 nov. 2016.

BARBOSA, M. Z. Biocombustíveis e Commodities Agrícolas. Análise e Indicadores do Agronegócio, n. Tabela 1, p. 9-12, 2014. Disponível em: <ftp://ftp.sp.gov.br/ftpiea/AIA/AIA30-2014.pdf>. Acesso em: 12 mar. 2016.

BIOGRACE.The BioGrace GHG calculation tool: a recognised voluntary scheme. 2015. Disponível em: <http://BioGrace.net/home>. Acesso em: 15 jul. 2016.

CHERUBINI, F.; STRØMMAN, A. H.; ULGIATI, S. Influence of allocation methods on the environmental performance of biorefinery products - A case study. Resources, Conservation and Recycling, v. 55, n. 11, p. 1070-1077, 2011. https://doi.org/10.1016/j.resconrec.2011.06.001.

COMISSÃO MUNDIAL SOBRE MEIO AMBIENTE E DESENVOLVIMENTO. Our Common Future , Chapter 2 : Towards Sustainable Development. p. 1-20, 1987. Disponível em: <http://www.onu.org.br/rio20/documentos/>. Acesso em: 10 mar. 2016.

CURRAN, M. A. A Review of Life-Cycle Based Tools Used to Assess the Environmental Sustainability of Biofuels in the United States. n. October, p. 61, 2013.

DENVIR, B. Sustainability Criteria for Biofuels. n. December, 2014. Disponível em:

Revista Produção Online. Florianópolis, SC, v.17, n. 2, p. 711-732, 2017. 
$<$ https://www.energy-

community.org/portal/page/portal/ENC_HOME/DOCS/3606189/Annex_I_WS_Slides.pdf>. Acesso em: 13 mar. 2016.

DEPEC- DEPARTAMENTO DE PESQUISA E ESTUDOS ECONÔMICOS. Açúcar e etanol. 2015. Disponível em:

<http://www.economiaemdia.com.br/EconomiaEmDia/pdf/infset_acucar_etanol.pdf>. Acesso em: 10 mar. 2016.

EMBRAPA- EMPRESA BRASILEIRA DE PESQUISA AGROPECUÁRIA. Quais são os países que mais emitem gases do efeito estufa? Disponível em:

<http://www.aquecimento.cnpm.embrapa.br/conteudo/historico_aq_paises.htm>. Acesso em: 10 mar. 2016.

ENMC. ENTIDADE NACIONAL PARA O MERCADO DE COMBUSTÍVEL.

Sustentabilidade. Disponível em: <http://www.enmc.pt/pt-

PT/atividades/biocombustiveis/entidade-coordenadora-do-cumprimento-dos-criterios-desustentabilidade--ecs-/sustentabilidade/>. Acesso em: 10 abr. 2016.

EPA- ENVIRONMENTAL PROTECTION AGENCY. Lifecycle Analysis of Greenhouse Gas Emissions under the Renewable Fuel Standard. Disponível em:

$<$ https://www.epa.gov/renewable-fuel-standard-program/lifecycle-analysis-greenhouse-gasemissions-under-renewable-fuel>. Acesso em: 15 mar. 2016.

EPA- UNITED STATES ENVIRONMENTAL PROTECTION AGENCY. Renewable Fuel Standard. 2014. Disponível em: <http://www.epa.gov/oms/fuels/renewablefuels/>. Acesso em: 15 mar. 2016.

EPA- UNITED STATES ENVIRONMENTAL PROTECTION AGENCY. Renewable Fuel Standard Program (RFS2) Regulatory Impact Analysis Program. [S.I: s.n.], 2010. Disponível em: <https://www.epa.gov/sites/production/files/201508/documents/420r10006.pdf>. Acesso em: 14 mar. 2016.

EUROPEAN COMMISSION. DIRECTIVA 2009/28/CE. Official Journal of the European Union. [S.I: s.n.]. , 2009

EUROPEAN COMMISSION. Renewable energy directive. p. 5-6, 2015. Disponível em: $<$ https://ec.europa.eu/energy/en/topics/renewable-energy>. Acesso em: 18 mar. 2016.

FEDERAL REGISTER. Regulation of fuels and fuel additives. United States: [s.n.]. Disponível em: <http://www.epa.gov/OMS/renewablefuels/rfs2_1-5.pdf>. Acesso em: 18 mar. 2016.

GRISOLI, R. Comparação das emissões de gases do efeito estufa no ciclo de vida do etanol de cana-de-açúcar no Brasil e os critérios da Diretiva Européia para Energias Renováveis. 2011.112 f. Universidade de São Paulo, 2011. Disponível em: < http://www.teses.usp.br/teses/disponiveis/86/86131/tde-10082011-152907/pt-br.php>. Acesso em: 12 mar. 2016.

ICTSD- INTERNATIONAL CENTRE FOR TRADE AND SUSTAINABLE DEVELOPMENT. Sustainability Criteria in the EU Renewable Energy Directive: Consistent with WTO Rules ? [S.I: s.n.], 2010. Disponível em:

$<$ http://www.ictsd.org/downloads/2011/12/sustainability-criteria-in-the-eu-renewable-energydirective-consistent-with-wto-rules.pdf>. Acesso em: 12 mar. 2016.

Revista Produção Online. Florianópolis, SC, v.17, n. 2, p. 711-732, 2017. 
MARCAL, L. M. et al. Fundamentos da Análise do Ciclo de Vida. Enegep, 2013.

MARCONI, M. DE A.; LAKATOS, E. M. Fundamentos de metodologia científica. 7. ed. São Paulo: Atlas, 2010.

NL AGENCY. Sustainability requirements for biofuels and biomass for energy in EU and US regulatory frameworks. [S.I: s.n.], 2011. Disponível em:

<http://english.rvo.nl/sites/default/files/2013/12/Report EU and US biomass legislation Partners for Innovation.pdf>. Acesso em: 10 mar. 2016.

NOVACANA. 2016. Cogeração: como funciona a produção de energia elétrica numa usina sucroalcooleira Disponível em: < https://www.novacana.com/usina/cogeracao-comofunciona-producao-energia-eletrica/>. Acesso em: 10 mar. 2016.

OECD/FAO. OECD-FAO Agricultural Outlook 2015. Paris: OECD Publishing, 2015. Disponível em: <http://www.oecd-ilibrary.org/agriculture-and-food/oecd-fao-agriculturaloutlook-2015/biofuels_agr_outlook-2015-13-en>. Acesso em: 06 jun. 2016.

QUEIROZ, G. D. C.; GARCIA, E. E. C. Reciclagem de sacolas plásticas de polietileno em termos de inventário de ciclo de vida. Polímeros, v. 20, n. 5, p. 401-405, 2010. https://doi.org/10.1590/S0104-14282011005000003

REIN, P. W. Sustainable sugar production. 2012. Disponível em: $<$ http://www.thermalenergysystems.com/bsst/papers/2012agm1.pdf>. Acesso em: 11 jul. 2016.

ROLLANO, C. R. L.; FONTES, C. H. O.; BARBOSA, A. S. Análise Da Evolução Do Desenvolvimento Sustentável Nas Indústrias Produtoras De Biocombustíveis No Brasil. 2015. http://dx.doi.org/10.14488/1676-1901.v15i2.1938

SCHNEPF, R.; YACOBUCCI, B. D. Renewable Fuel Standard ( RFS ): Overview and Issues. CRS Report for Congress. 2013. Disponível em: <http://fas.org/sgp/crs/misc/R40155.pdf>. Acesso em: 11 mar. 2016.

UNICA. 60 países já adotaram mistura obrigatória de biocombustíveis aos combustíveis fósseis. p. 2-3, 2014. Disponível em: <http://www.unica.com.br/noticia/27251092920325965467/60-paises-ja-adotam-misturaobrigatoria-de-biocombustiveis-aos-combustiveis-fosseis/>. Acesso em: 14 mar. 2016.

UNICA. EPA REAFFIRMS SUGARCANE BIOFUEL IS ADVANCED RENEWABLE FUEL WITH $61 \%$ LESS EMISSIONS THAN GASOLINE. Disponível em: <http://www.unica.com.br/news/38990375920334398749/epa-reaffirms-sugarcane-biofuel-isadvanced-renewable-fuel-with-61-por-cento-less-emissions-than-gasoline/>. Acesso em: 13 mar. 2016.

UNICADATA. HISTÓRICO DE PRODUÇÃO DO ETANOL NO BRASIL. Disponível em: $<$ http://www.unicadata.com.br/historico-de-producao-emoagem.php?idMn=31\&tipoHistorico=2\&acao=visualizar\&idTabela=1611\&produto=etanol to tal\&safralni=2000/2001\&safraFim $=2013 / 2014$ \&estado=RS,SC,PR,SP,RJ,MG, ES,MS,MT,GO ,DF,BA,SE,AL,PE,PB,RN,CE,PI,MA,TO,PA,AP,RO,>. Acesso em: 10 mar. 2016.

VON BLOTTNITZ, H.; CURRAN, M. A. A review of assessments conducted on bioethanol as a transportation fuel from a net energy, greenhouse gas, and environmental Revista Produção Online. Florianópolis, SC, v.17, n. 2, p. 711-732, 2017. 
life cycle perspective. Journal of Cleaner Production, v. 15, n. 7, p. 607-619, 2007.

Disponível em: < http://www.sciencedirect.com/science/article/pii/S0959652606001016>. Acesso em: 23 jul. 2016.

WANG, M. et al. Well-to-wheels energy use and greenhouse gas emissions of ethanol from corn, sugarcane and cellulosic biomass for US use. Environmental research letters, v. 7, n. 4, p. 045905, 2012. Disponível em: <http://stacks.iop.org/1748-

9326/7/i=4/a=045905? $\mathrm{key}=$ crossref.bc2d92022ddca565108ad62fb6e4201d $>$. Acesso em: 15 mar. 2016.

WBA. WORLD BIOENERGY ASSOCIATION. Biofuels for Transport. 2013. Disponível em: $<$ http://www.worldbioenergy.org/sites/default/files/Biofuels_for_Transport_short_version_0.pd f>. Acesso em: 22 jul. 2015.

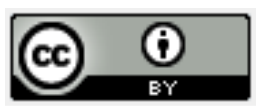

Artigo recebido em 15/02/2017 e aceito para publicação em 18/04/2017

DOI: http://dx.doi.org/10.14488/1676-1901.v17i2.2730 